\title{
Root and Foot Rot of Loquat in Taiwan Caused by Phytophthora
}

L. L. Chern, Culture Collection Center, Food Industry and Research Institute, HsinChu, Taiwan, P. J. Ann, Taiwan Agricultural Research Institute, Wufeng, Taiwan, and H. R. Young, Chiayi Agricultural Experimental Station, Chiayi, Taiwan

\begin{abstract}
Chern, L. L., Ann, P. J., and Young, H. R. 1998. Root and foot rot of loquat in Taiwan caused by Phytophthora. Plant Dis. 82:651-656.

Loquat trees growing in central Taiwan were inflicted with a disease causing wilting and death of plants due to severe foot and root rot. The vascular tissues of all infected plants turned brown. Typical as well as atypical isolates of Phytophthora parasitica were isolated from the diseased basal stem and root tissues but not from the discolored vascular tissues. Symptoms observed in the field were reproduced when roots and stems of loquat seedlings were inoculated with zoospores of atypical isolates of $P$. parasitica; whereas only fibrous root rot resulted from inoculation with typical isolates of $P$. parasitica. Atypical isolates could be differentiated from the typical isolates of $P$. parasitica by several characteristics, including colony appearance, partial caducous sporangia, size of oospore, growth at $36^{\circ} \mathrm{C}$, mycelial soluble protein patterns, and pathogenicity.
\end{abstract}

Additional keywords: atypical strain

Loquat (Eriobotrya japonica (Thunb.) Lindl.), a delicate fruit with bright orange color and juicy fragrant taste, is a popular choice among the fruits marketed in Taiwan in the spring. This crop is cultivated mainly in central Taiwan, with an annual production of 9,850 t from 1,350 ha (11). In 1995, loquat trees growing in several orchards suffered severe damage due to foot and root rot. The plants eventually died. Disease symptoms were first observed in an experimental field at the Taiwan Agriculture Research Institute and later at Hsinshe in Taichung County and Yungching in Changhua County. About $40 \%$ of 3-year-old loquat trees in one orchard and $20 \%$ of 7-year-old loquat trees in another orchard died as a result of this disease. Further investigation indicated that Phytophthora was associated with the disease. Morphological and physiological characteristics of the isolated fungi enabled us to identify some of the isolates based on taxonomic keys described by Tucker (12) or Waterhouse (13). However, there were isolates with characteristics that did not completely fit those of any described species, making proper identification difficult. Since soluble protein patterns were used to differentiate six species of Phytophthora (2) and oligonucleotide probes cloned from specific DNA fragments were used for the

Corresponding author: L. L. Chern

E-mail: 1lchern@ccrc.firdi.org..tw

Accepted for publication 23 February 1998.

Publication no. D-1998-0406-02R

(C) 1998 The American Phytopathological Society detection and identification of Phytophthora species (4), we applied these molecular technologies to assist in the identification of the pathogen. We report here the isolation, identification, and pathogenicity of the fungi responsible for a new disease of loquat in Taiwan.

\section{MATERIALS AND METHODS}

Isolation of microorganisms. Diseased roots and basal stems of E. japonica were collected from orchards at Wufeng and Hsinshe in Taichung County and Yungching in Changhua County. Samples were washed under tap water, trimmed to approximately 5 to $10 \times 5 \times 5 \mathrm{~mm}$, surface-sterilized with $0.5 \% \mathrm{NaClO}$ for $3 \mathrm{~min}$, and air-dried on paper towels. Three to five pieces of plant tissues were placed in a petri plate $(9 \mathrm{~cm}$ diameter) containing 20 $\mathrm{ml}$ of a selective medium (8) and incubated at $25^{\circ} \mathrm{C}$. The selective medium consisted of 5\% clarified Campbell's V8 juice and $2 \%$ Bacto agar, which after autoclaving was supplemented with 100 ppm ampicillin, $50 \mathrm{ppm}$ mycostatin, and $10 \mathrm{ppm}$ pentachloronitrobenzene. Clarified V8 juice was prepared by centrifuging Campbell's V8 juice mixed with $0.2 \% \mathrm{CaCO}_{3}$ at 1,500 rpm for $5 \mathrm{~min}$ and collecting the supernatant immediately afterward. Mycelia with characteristics of the genus Phytophthora growing from diseased tissues were transferred to 5\% V8 agar (5\% Campbell's V8 juice, $0.02 \% \mathrm{CaCO}_{3}$, and $2 \%$ Bacto agar). All isolates were purified by single zoospore isolation before use in the following studies.

The following fungal isolates were used in the molecular studies for comparison: Phytophthora palmivora (E.J. Butler) E.J.
Butler isolate 92133 from Cymbidium oiwakensis Hay, P. palmivora isolate Dalien from Dendrobium sp., $P$. palmivora isolate ATCC6144 from loquat seedling, $P$. parasitica Dastur isolate 6133 from Solanum melongena L., P. citrophthora (R.E. Sm. \& E.H. Sm.) Leonian isolate 9250 from Hoya carnosa (L.) Brown, and P. megasperma Drechs. isolate 96004 from Cymbidium sp.

Morphological studies. To study the colony type, test isolates were grown on $5 \%$ clarified V8 agar (5\% clarified Campbell's V8 juice and 2\% Bacto agar) at $25^{\circ} \mathrm{C}$. Hwang and Ko's method (6) was used to stimulate the production of sporangia and zoospores for morphological and inoculation study. Ten culture plugs (approximately $2 \times 2 \times 2 \mathrm{~mm}$ ) cut from the actively growing margin of colonies on V8 agar were transferred onto a sterile cellophane membrane $(9 \mathrm{~cm}$ diameter) previously placed on a $10 \%$ V8 agar $(10 \%$ V8 juice, $0.02 \% \mathrm{CaCO}_{3}, 2 \%$ Bacto agar) plate. After incubation at $25^{\circ} \mathrm{C}$ for $24 \mathrm{~h}$, the cellophane membrane with mycelia was moved to a petri plate containing $20 \mathrm{ml}$ of $5 \%$ V8 broth (5\% Campbell's V8 juice and $0.02 \% \mathrm{CaCO}_{3}$ ) and incubated at $25^{\circ} \mathrm{C}$ for $24 \mathrm{~h}$. The V8 broth was drained off, and the mycelia on the cellophane membrane were washed three times, each with $20 \mathrm{ml}$ of mineral solution $\left(0.236 \% \quad \mathrm{Ca}\left(\mathrm{NO}_{3}\right)_{2}\right.$, $0.05 \% \quad \mathrm{KNO}_{3}, \quad 0.0985 \% \quad \mathrm{MgSO}_{4}$, and $0.046 \%$ FeEDTA added after autoclave). Following incubation for $9 \mathrm{~h}$ under fluorescent light, the mineral solution was replaced by sterile distilled water, and the plate was incubated in the same condition for an additional $15 \mathrm{~h}$, placed in $10^{\circ} \mathrm{C}$ for $30 \mathrm{~min}$, then returned to $24^{\circ} \mathrm{C}$ to release zoospores.

To determine mating type, each isolate of Phytophthora was grown on $10 \% \mathrm{~V} 8$ agar at $24^{\circ} \mathrm{C}$ in darkness for 10 days. Those isolates forming oospores in single cultures were designated as homothallic. Others were paired individually with the standard A1 (P991) and A2 (P731) mating types of $P$. parasitica. Both P731 and P991 were isolated from citrus by G. A. Zentmyer. Those forming oospores when paired with the A2 tester were designated as A1, and those forming oospores with the A1 tester were A2. The polycarbonate membrane method described by Ko (7) was used for sexual reproduction of homothallic as well as heterothallic isolates of Phytophthora. A 6-day-old culture block $(10 \times$ $15 \times 3 \mathrm{~mm}$ ) of each isolate to be tested was placed in the center of a petri dish $(9 \mathrm{~cm}$ 
diameter) and covered with a sterile polycarbonate membrane $(0.2 \mu \mathrm{m}, 90 \mathrm{~mm}$ diameter; Nuclepore, Pleasanton, CA). Each culture block was paired with the same size culture block of P991 or P731 across the membrane. After incubation at $24^{\circ} \mathrm{C}$ in darkness for 6 days, the testers were removed and the culture blocks were examined under the microscope. Fifty measurements were made to determine the sizes of each reproductive structure.

Growth of fungi. To study growth at different temperatures and growth rates of the fungi isolated from loquat, tested isolates were subcultured by transferring a culture disk (6 $\mathrm{mm}$ diameter) of each isolate to a $5 \%$ V8 agar plate $(90 \mathrm{~mm}$ diameter) and incubating at $10,12,15,18,21$, $24,27,30,33,35$, or $36^{\circ} \mathrm{C}$. Linear growth of each isolate was measured daily up to 7 days or until the agar plate was overgrown. There were three replicates for each temperature.

Soluble protein patterns. To extract soluble protein from mycelia, tested isolates were grown in $25 \mathrm{ml}$ of $10 \% \mathrm{~V} 8$ broth (10\% Campbell's V8 juice and $0.02 \%$ $\mathrm{CaCO}_{3}$ ) for 7 to 10 days at $24^{\circ} \mathrm{C}$ in darkness. Mycelial mats from three 250-ml flasks per isolate were harvested by filtering through Whatman no. 1 filter paper in a Buchner funnel, washed with $0.1 \mathrm{M}$ phosphate buffer $(\mathrm{pH} 7)$, vacuum dried, and frozen at $-20^{\circ} \mathrm{C}$ before use. The soluble proteins were extracted by grinding the mycelial mats with a prechilled mortar and pestle. A pinch of acid-washed sand was added to assist homogenization. The homogenate was centrifuged at $9,200 \times g$ for $30 \mathrm{~min}$. Electrophoresis of soluble protein extracts was run under a sodium dodecyl sulfate (SDS) discontinuous system (10). The soluble protein extracts were diluted
1:4 (wt/vol) with SDS reducing buffer, followed by heating in boiling water for 4 min. The electrophoresis was conducted using a $4.0 \%$ polyacrylamide stacking gel and a $10.5 \%$ separating gel in a vertical slab mold $(16 \times 20 \times 0.75 \mathrm{~cm})$. Aliquots of $10 \mu \mathrm{l}$ of dissociated fungal proteins were loaded into wells in the gel. Electrophoresis was executed for 4 to $5 \mathrm{~h}$ at room temperature powered by BIO-RAD Model 3000 xi Power Supply (BIO-RAD Laboratories, Richmond, $\mathrm{CA}$ ) at $20 \mathrm{~mA}$ for the stacking gel and at $28 \mathrm{~mA}$ for the separating gel. Gels were stained with $0.1 \%$ Coomassie blue G250 in fixative $(40 \%$ methanol and $10 \%$ acetic acid) for $30 \mathrm{~min}$ and destained with the fixative until the background was clean.

Polymerase chain reaction (PCR) amplification of genomic DNA using species-specific primers. DNA extracted from homothallic isolates 96012 and 95023 were compared with those from isolates P991 and P731 of P. parasitica and other species using PCR with a pair of $P$. parasitica species-specific primers (4). DNA was extracted from mycelia as described elsewhere (3). PCR amplification of genomic DNA with primers of 24-bp oligonucleotides, PAR1 and PAR2, was performed with an Idaho Air Thermal Cycler. The primers were obtained from R. F. Liu of National Taiwan University. PCR conditions used were modified from those described by Ersek et al. (4). A 10- $\mu$ l reaction mixture in $50 \mathrm{mM}$ Tris- $\mathrm{HCl}$ buffer, consisting of $20 \mathrm{mM} \mathrm{KCl}, 2.5 \mathrm{mM} \mathrm{MgCl}{ }_{2}$, $0.5 \mathrm{mg}$ of BSA per ml, $200 \mu \mathrm{M}$ each dNTP, $10 \mu \mathrm{M}$ of each primer, $30 \mathrm{ng}$ of template DNA, and 1.7 unit of Taq DNA polymerase (Boehringer Mannheim Biochemica), was sealed in a $10-\mu$ l glass capillary with a gas gun. Reactions were

Table 1. Isolation of Phytophthora spp. from loquat in Taiwan

\begin{tabular}{lllccc}
\hline $\begin{array}{l}\text { Collection } \\
\text { date }\end{array}$ & \multicolumn{1}{c}{ Location } & \multicolumn{1}{c}{ Plant tissues } & $\begin{array}{c}\text { Isolates } \\
\text { obtained }\end{array}$ & Species & $\begin{array}{c}\text { Mating } \\
\text { type }\end{array}$ \\
\hline 20 Nov 1995 & Wufeng, field 1 & Basal stems & $95023-95029$ & parasitica & $\mathrm{H} \rightarrow \mathrm{A}^{\mathrm{a}}$ \\
11 Dec 1995 & Wufeng, field 2 & Basal stems, roots & $95030-95038$ & parasitica & $\mathrm{H} \rightarrow \mathrm{A} 2$ \\
10 Jan 1996 & Wufeng, field 3 & Roots & $96011-96012$ & parasitica & $\mathrm{H} \rightarrow \mathrm{A} 2$ \\
5 Sep 1996 & Yungching & Basal stems, roots & $96085-96090$ & parasitica & $\mathrm{A} 2$ \\
12 Sep 1996 & Wufeng & Stems & $96091-96095$ & parasitica & $\mathrm{A} 1$ \\
5 Dec 1996 & Hsinshe & Stems & $96120-96121$ & parasitica & $\mathrm{A} 2$ \\
\hline
\end{tabular}

${ }^{a}$ Isolates produced few oospores singly but formed a large number of oospores when paired with the A1 isolate (P991) of P. parasitica. cycled 39 times with temperate denaturation at $94^{\circ} \mathrm{C}$ for $1 \mathrm{~min}$, primer annealing at $65^{\circ} \mathrm{C}$ for $2 \mathrm{~min}$, and primer extension at $72^{\circ} \mathrm{C}$ for $3 \mathrm{~min}$. One cycle of denaturation at $94^{\circ} \mathrm{C}$ for $5 \mathrm{~min}$ was run before and one extension at $72^{\circ} \mathrm{C}$ for $10 \mathrm{~min}$ was run after these cycles. Products of PCR were analyzed by electrophoresis on a $1.5 \%$ agarose gel (Nusieve agarose 3:1, FMC Bioproducts) with $1 \times$ TBE buffer $(\mathrm{pH} 8.3)$ at $150 \mathrm{~V}$ for $3 \mathrm{~h}$. Gels were stained with ethidium bromide. Bands were visualized with a UV transilluminator.

Pathogenicity tests. Isolates 95023, 95034, and 96091 from Wufeng, isolate 96085 from Yungching, and 96120 from Hsinshe were used in pathogenicity tests. Isolate ATCC6144 of P. palmivora isolated from loquat seedlings in a nursery at Yungching was used for comparison. Three-month-old loquat seedlings were used for root inoculation. Twenty $\mathrm{ml}$ of zoospore suspension was added to a pot of 10 loquat seedlings; two pots were used for each tested isolate. Seedlings inoculated with sterile distilled water were used as a control. Zoospore suspensions were adjusted to $10^{5}$ to $10^{6}$ zoospores per $\mathrm{ml}$ by microliter syringe method (9). After incubation for 1 month, roots of inoculated plants were surface-sterilized with $0.5 \%$ $\mathrm{NaClO}$ and placed on selective medium as described previously.

Pathogenicity on basal stems of loquat was performed by inoculating 1-year-old seedlings. Fifty $\mu$ l of zoospore suspension absorbed in a cotton ball was placed on the loquat stem and wrapped with a plastic sheet to retain moisture. Cotton balls containing sterile distilled water were used as a control. Disease severity was recorded after 30 days, and tissue obtained from margins of the lesions was used to reisolate the tested isolates.

Pathogenicity of loquat isolates to other plants was also studied. All the seedlings used for inoculation were 2 to 4 weeks old. Potted seedlings of tomato (Lycopersicon esculetum Mill.), sweet pepper (Capsicum annuum L. var. grossum Seudt.), cucumber (Cucumis sativus L.), and tobacco (Nicotiana tabacina L.) were inoculated with $1 \mathrm{ml}$ of zoospore suspension. Disease incidence was recorded after 2 weeks. Roots of sweet orange (Citrus sinensis Osb.) seedlings were dipped in $20 \mathrm{ml}$ of

Table 2. Characteristics of isolates of Phytophthora isolated from loquat

\begin{tabular}{|c|c|c|c|c|c|c|c|}
\hline \multirow[b]{2}{*}{ Isolate no. } & \multicolumn{3}{|c|}{ Sporangia $(\mu \mathrm{m})$} & \multirow{2}{*}{$\begin{array}{c}\text { Diameter of } \\
\text { oogonia }(\mu \mathrm{m})\end{array}$} & \multirow{2}{*}{$\begin{array}{c}\text { Diameter of } \\
\operatorname{oospores}^{\mathrm{a}}(\mu \mathrm{m})\end{array}$} & \multirow{2}{*}{$\begin{array}{c}\text { Antheridia } \\
(\mu \mathrm{m})\end{array}$} & \multirow{2}{*}{$\begin{array}{c}\text { No. of } \\
\text { oospores } / \mathrm{cm}^{2}\end{array}$} \\
\hline & Length & Width & $\mathbf{l} / \mathbf{b}$ & & & & \\
\hline 95023 & $54.2^{\mathrm{b}}$ & 40.1 & 1.36 & 33.8 & 29.6 & $11.1 \times 14.1$ & 7,657 \\
\hline 95034 & 49.3 & 40.1 & 1.25 & 35.5 & 30.9 & $11 \times 13.9$ & 6,462 \\
\hline 96012 & 51.0 & 40 & 1.4 & 33.7 & 29.6 & $\mathrm{NT}^{\mathrm{c}}$ & NT \\
\hline 96085 & 50 & 41.5 & 1.21 & 27.9 & 22.2 & $12.1 \times 13.8$ & 9,490 \\
\hline 96091 & 43.1 & 35.5 & 1.22 & 24.2 & 20.6 & $11.5 \times 12.7$ & 32,570 \\
\hline 96120 & 45.6 & 36.7 & 1.24 & 33.2 & 27.6 & $12.7 \times 15.4$ & 5,703 \\
\hline
\end{tabular}

a Oospores were stimulated by opposite mating type with polycarbonate membrane method (7).

b Each number represents average of 50 measurements.

c Not tested. 
inoculum for $24 \mathrm{~h}$ and replanted in sand. Root rot was determined 1 month later. Fruits of eggplant were inoculated by inserting a mycelial block $(5 \mathrm{~mm}$ diameter and $2 \mathrm{~mm}$ thick) into a hole of the same size made by a sterile scalpel. Pathogenicity was rated as follows: +++ = highly virulent, lesion appeared in 2 days; $++=$ moderately virulent, lesion appeared in 3 to 5 days; $+=$ weakly virulent, lesion appeared after 5 to 7 days; $-=$ no lesion developed in 7 days.

All experiments were repeated at least once. One set of data from each repeated experiment with similar results was presented.

\section{RESULTS}

Disease symptoms in the field. Infected loquat trees exhibited symptoms of tree decline, with yellow leaves in the early stages and leaves turning brown as the disease advanced. Defoliation was observed in the case of slow decline. Occasionally, usually after a heavy rainfall, some of the trees collapsed rather rapidly, leaving the brown leaves hanging on the dead trees. Many of the roots of infected trees were rotten and turned dark brown. Discoloration also was observed on the stem, starting from the base up to $1 \mathrm{~m}$ aboveground. Infected bark was rough and grayish brown, in contrast to the smooth and light brown bark of healthy trees. Vascular tissue underneath was necrotic and red-brown instead of healthy white. There was a distinct border between healthy and diseased tissues.

Isolation of the fungi associated with disease. We collected samples four times from Wufeng and once each at Yungching and Hsinshe. Phytophthora was isolated on every occasion. The results of isolations are summarized in Table 1. All isolates obtained during the same collection time were very similar. One isolate representing each collection was selected for cultural studies. Among the 31 isolates recovered from diseased tissues, 13 of them (isolates 96085-96095 and isolates 96120-96121) were heterothallic. Isolates 96085 (A2), 96091 (A2), and 96120 (A1) produced no oospores alone, but when paired with $\mathrm{P} 991$ (A2) or P731 (A2) of $P$. parasitica, they produced $9,490,32,570$, and 5,703 oospores per $\mathrm{cm}^{2}$, respectively (Table 2). The oogonia were spherical and smooth and averaged $27.9,24.2$, and $33.2 \mu \mathrm{m}$ in diameter, respectively, with single, monocellular, amphigynous antheridia. The oospores were spherical with a thick wall, nearly or loosely filling the oogonia, and measured 22.2, 20.6, and $27.6 \mu \mathrm{m}$ in diameter for isolates 96085, 96091, and 96120, respectively (Table 2). The colony patterns of these isolates appeared mosaic on 5\% clarified V8 agar. Abundant sporangia were formed on solid media $(10 \% \mathrm{~V} 8$ agar) as well as on culture blocks submerged in water. Sporangia were spherical, ovoid to ovoid-obpyriform, and noncaducous with mostly one and sometimes two distinct semispherical papillae. They measured 43.1 to $50 \times 35.5$ to $41.5 \mu \mathrm{m}$ in size with $1 / \mathrm{b}$ ratio 1.21 to 1.24 (Table 2 ). Sporangiophores were simple sympodia. Isolates 96085 and 96091 grew at temperatures from 12 to $36^{\circ} \mathrm{C}$, with optimum temperatures of 24 to $28^{\circ} \mathrm{C}$ (Fig. 1), and growth rates at $36^{\circ} \mathrm{C}$ were 0.4 and 0.5 $\mathrm{cm} /$ day, respectively. However, no growth was observed for 96120 at $36^{\circ} \mathrm{C}$ (Fig. 1). The physiological and morphological characteristics of these isolates agreed with those of $P$. parasitica described by Tucker (12) and Waterhouse (13). Hence, isolates 96085 and 96091 were identified as typical of $P$. parasitica. Isolate 96120 also was identified as $P$. parasitica but as atypical due to the large size of its oospores and its inability to grow at $36^{\circ} \mathrm{C}$.

The rest of the isolates (representing 95023, 95034, and 96012), all from Wufeng, were able to produce a few oospores (a few hundred per $\mathrm{cm}^{2}$ ) alone. They also stimulated the A1 mating type tester of $P$. parasitica to produce oospores but not the A2 mating type. When paired across a polycarbonate membrane with the A1 tester, these isolates produced 6,462 to 7,567 oospores per $\mathrm{cm}^{2}$ (Table 2). The shapes of oogonia, antheridia, and oospores were similar to those of the heterothallic isolates of $P$. parasitica from loquat. However, the sizes of oogonia and oospores were much larger. Oogonia and oospores of isolate 95023 averaged 33.8 and $29.6 \mu \mathrm{m}$ in diameter, respectively, and those of isolates 95034 were 35.5 and 30.9 $\mu \mathrm{m}$ (Table 2). The sizes of oospores resulting from pairing across a polycarbonate membrane and those without pairing were similar. Colonies on 5\% clarified V8 agar were uniform or radiate, similar to those of $P$. palmivora. They also produced ample sporangia on solid agar as well as in water. The sizes and shapes of sporangia were similar to those produced by heterothallic isolates of $P$. parasitica (Table 2) rather than the isolate of $P$. palmivora. However, about $50 \%$ of the sporangia were caducous with pedicel $\leq 5 \mu \mathrm{m}$. Homothallic isolates 95023 and 95034 grew from 10 to $33^{\circ} \mathrm{C}$, with optimum growth at temperatures between 24 and $33^{\circ} \mathrm{C}$. They failed to grow at $35^{\circ} \mathrm{C}$ or above (Fig. 1). Physiological and morphological characteristics of these homothallic isolates did not match well with any known species of Phytophthora based on the descriptions of type cultures or comparison with standard isolates.

Soluble proteins patterns. Soluble protein patterns divided $P$. parasitica isolates from loquat into two groups (Fig. 2). The homothallic isolates 95023, 95034, and 96012 (lanes 6 to 8) and one heterothallic isolate, 96120 (lane 5), were in the same group; whereas the other two heterothallic isolates, 96085 and 96092, formed a group similar to the soluble protein patterns produced by P991 and P731. The two groups differed only in one band

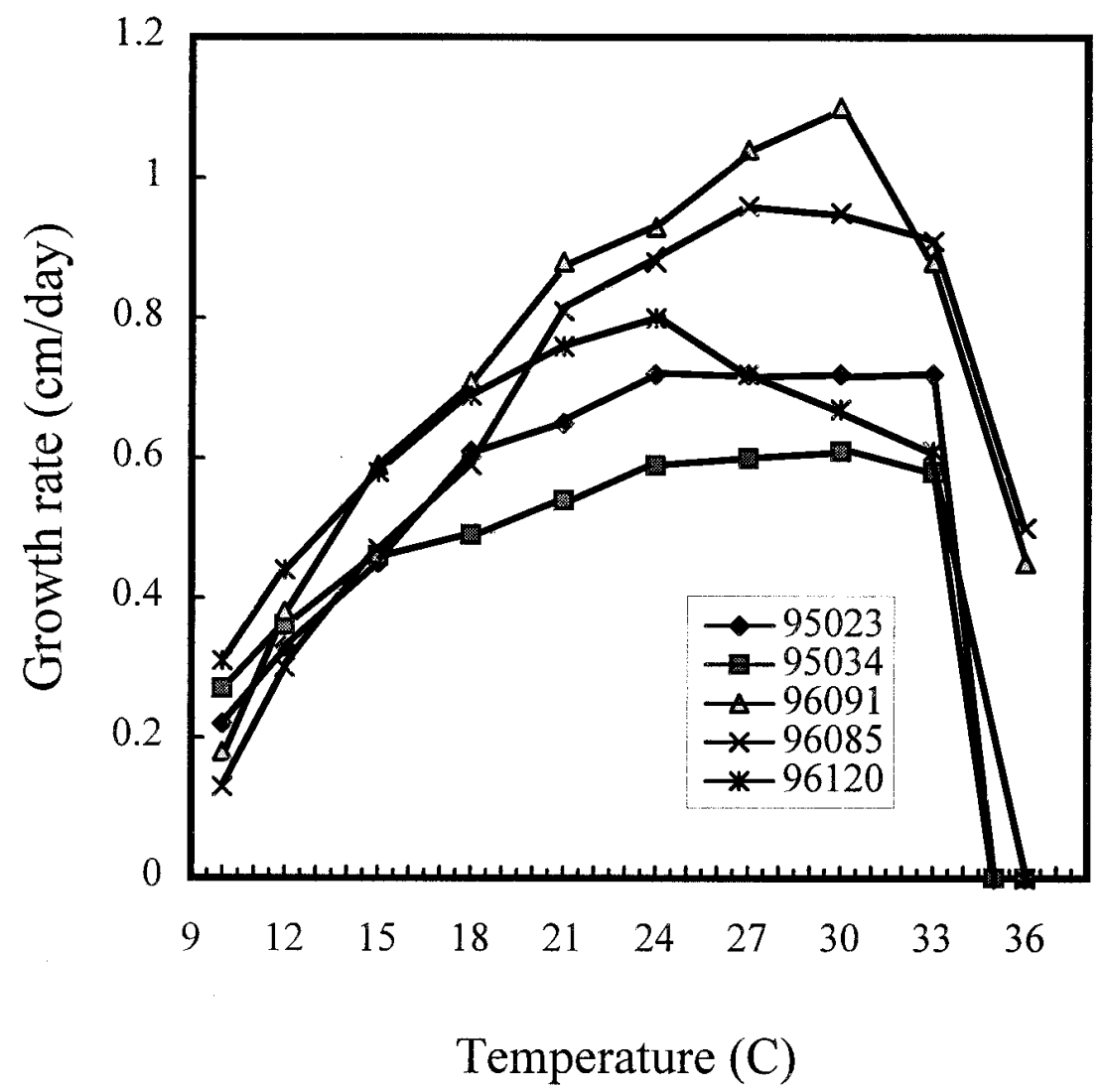

Fig. 1. Linear growth of isolates of Phytophthora parasitica on 5\% clarified V8 agar. 
(Fig. 2). The two isolates of $P$. palmivora produced identical soluble protein patterns that were distinct from those produced by the $P$. parasitica isolates.

PCR amplification of genomic DNA. The $P$. parasitica species-specific primers, PAR1 and PAR2, amplified a special 1,000-bp sequence along with other sequences of DNA isolated from 96012,
95023, and standard isolates P991 and P731 of $P$. parasitica. The primers did not amplify this 1,000-bp sequence with DNA isolated from $P$. palmivora or other species of Phytophthora (Fig. 3).

According to these results, homothallic isolates represented by 95023,95034 , and heterothallic 96120 were identified as atypical $P$. parasitica.

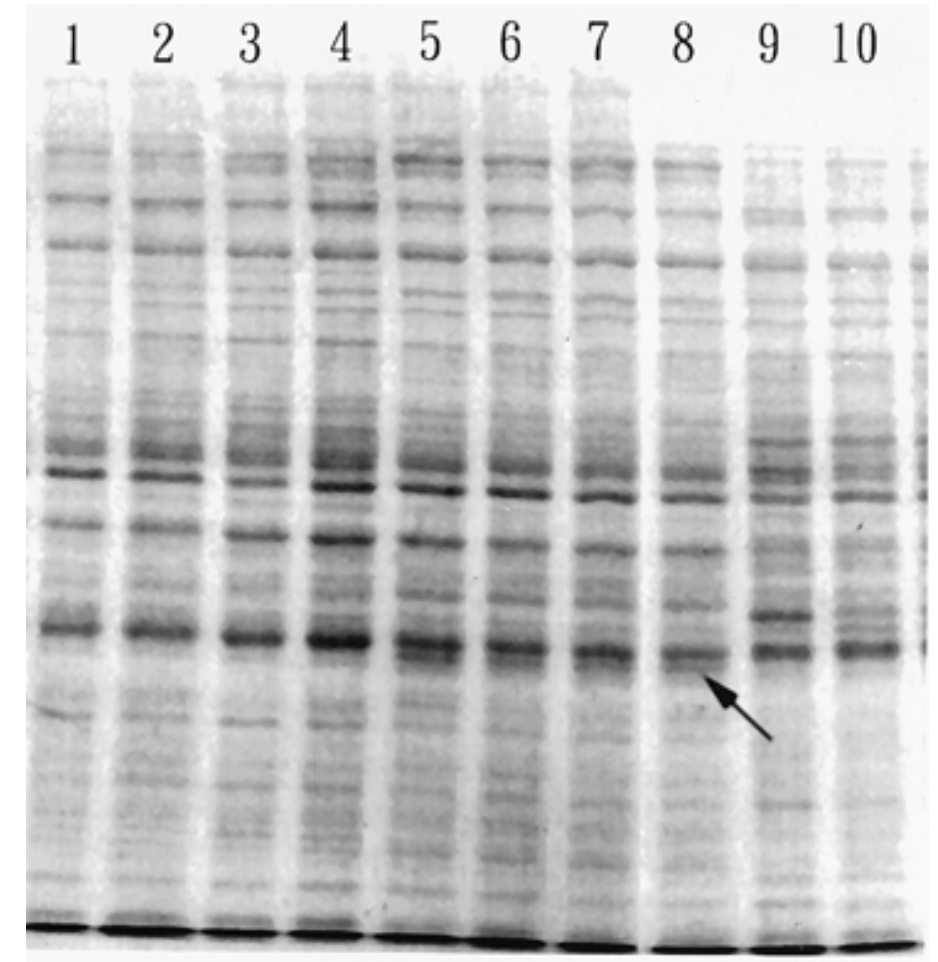

Fig. 2. Soluble protein patterns for isolates of Phytophthora parasitica and P. palmivora generated by electrophoresis of sodium dodecyl sulfate (SDS)-dissociated proteins. Lanes 1 and 2, standard $P$. parasitica isolates P991 and P731; lanes 3 to 8, loquat isolates of $P$. parasitica 96085, 96092, 96120, 95023, 95034, and 96012; lanes 9 and 10, P. palmivora isolates ATCC6144 and 92133. Arrow indicates a band that differentiates typical $P$. parasitica isolates from atypical ones.

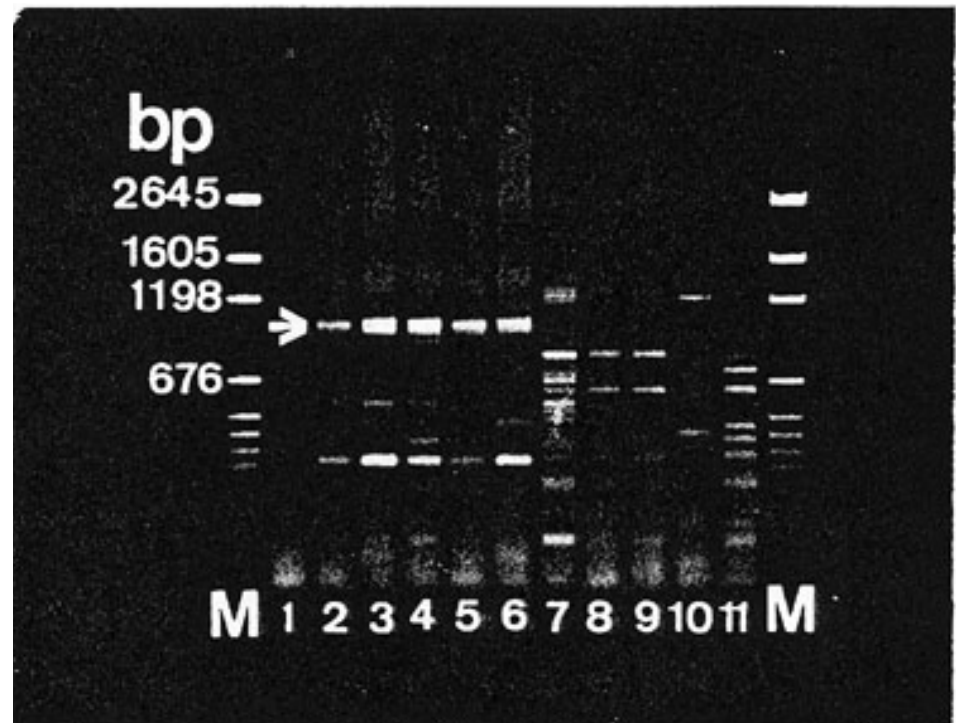

Fig. 3. Amplification of DNA with Phytophthora parasitica-specific primers. DNA were extracted from mycelia of various Phytophthora species. Lane 1, blank; lanes 2 to 6, P. parasitica isolates P991, P731, 95023, 96012, and ATCC6134; lanes 7 to 9, P. palmivora isolates 6144, Dalien, and 92133; lane 10, P. citrophthora; lane 11, P. megasperma. Arrow indicates the 1,000-bp band amplified specifically from DNA of $P$. parasitica.

Pathogenicity test. All the tested isolates of $P$. parasitica were able to infect roots of loquat seedlings (Table 3). Inoculation with atypical isolates 95023,95034 , and 96120 eventually caused death of loquat seedlings. Inoculation with typical isolates 96085 and 96091, however, only produced fibrous root rot. In the stem inoculation test, 95023 and 95034 caused the highest disease severity, with all the inoculated loquat plants killed in 30 days (Table 3). They were followed by 96120 , which caused death of $75 \%$ of the inoculated plants. Isolates 96085 and 96091 were unable to cause damage to the inoculated stems. The same fungus used for inoculation was reisolated from diseased and dead loquat seedlings.

All the tomato seedlings were killed within 2 weeks after inoculation with isolates 96085 (Table 4). Four out of five tomato seedlings died after inoculation with 96091. None of the seedlings were killed by atypical isolates of 95023 and 95034. None of the tested isolates were pathogenic on sweet pepper, cucumber, or tobacco plants (Table 4). Isolates 96085 and 96091 were highly virulent to sweet orange and eggplant fruits; whereas atypical isolates 95023, 95034, and 96120 were moderately or weakly virulent (Table 4).

\section{DISCUSSION}

This is the first formal report of a Phytophthora disease of loquat in Taiwan. The first isolation of Phytophthora was from seedlings with symptoms of damping-off in a loquat nursery at Yungching, Changhua County, in 1980 (5), and the fungus was subsequently identified as $P$. palmivora (ATCC6144) (1). Since 1995, a large number of loquat seedlings and trees have been found dead in nurseries and orchards after heavy rainfall. Because Phytophthora spp. were frequently isolated from diseased tissues, it appeared that Phytophthora was associated with the death of loquat trees in Taiwan. In pathogenicity tests, homothallic isolates (95023 and 95034) of $P$. parasitica were shown to be able to cause foot and root rot, resulting in death of all inoculated seedlings within a short period of time. An A2 isolate, 96120, of $P$. parasitica also killed $75 \%$ of the inoculated seedlings within 1 month. All three tested isolates of $P$. parasitica caused disease symptoms similar to those occurring in field conditions. However, P. parasitica isolates 96085 (A2) and 96091 (A1), and $P$. palmivora isolate ATCC6144 (A1) only caused fibrous root rot of inoculated seedlings.

When the disease occurred in Lebanon during the 1960s, Weltzien and Schwinn (14) isolated Phytophthora from the trunks of diseased plants and proved pathogenicity. The fungus was identified as $P$. parasitica according to cultural studies. Both homothallic and heterothallic strains were isolated in Lebanon. They were identical 
except for the ability to produce oospores in single cultures (14). They all produced papillate sporangia, which were attached to sporangiophores with very short pedicels. Oospores produced by the homothallic strains measured 24.3 to $35.4 \mu \mathrm{m}$ in diameter. These characteristics were similar to those of the homothallic isolates found in Taiwan, which were considered by us to be beyond the normal range of variation of the typical $P$. parasitica. Generally, typical $P$. parasitica is characterized by mosaic colonial patterns on V8 agar, nondeciduous sporangia without pedicels, heterothallic, and relatively small oospores, usually less than $30 \mu \mathrm{m}$ in diameter. Moreover, typical $P$. parasitica could grow at $36^{\circ} \mathrm{C}$, unlike our homothallic isolates and the A2 isolate

Table 3. Pathogenicity of loquat isolates of Phytophthora parasitica to loquat seedlings

\begin{tabular}{lcc}
\hline & \multicolumn{2}{c}{ Disease incidence } \\
\cline { 2 - 3 } Isolate no. & $\begin{array}{c}\text { Root } \\
\text { inoculation }^{\mathbf{a}}\end{array}$ & $\begin{array}{c}\text { Stem } \\
\text { inoculation }^{\mathbf{b}}\end{array}$ \\
\hline Typical P. parasitica & \\
96085 & $11 / 20$ & $0 / 6$ \\
96091 & $8 / 20$ & $0 / 6$ \\
Atypical P. parasitica & \\
95023 & $20 / 20$ & $6 / 6$ \\
95034 & $20 / 20$ & $6 / 6$ \\
96120 & $19 / 20$ & $3 / 4$ \\
P. palmivora & & \\
ATCC6144 & $5 / 20$ & $0 / 6$ \\
\hline
\end{tabular}

a No. of plants infected per no. of plants inoculated; 6-month-old seedlings were used.

${ }^{b}$ No. of plants killed per no. of plants inoculated; 1- to 2-year-old seedlings were used.
96120 (Fig. 1). On the other hand, characteristics of $P$. palmivora, such as inability to grow at $36^{\circ} \mathrm{C}\left(\max .34\right.$ to $\left.35^{\circ} \mathrm{C}\right)$ and mean sizes of oospores larger than $30 \mu \mathrm{m}$ diameter, were similar to those of the homothallic isolates. Despite these unusual cultural characteristics, soluble proteins patterns of 95023, 95034, and 96012 were closer to those of the standard isolates of $P$. parasitica (P991 and $\mathrm{P} 731$ ) than to those of $P$. palmivora (Fig. 2). DNA studies also gave further strong evidence that these homothallic isolates were closer to $P$. parasitica. When $P$. parasitica-specific primers were used to amplify genomic DNA, PCR amplified a species-specific band $(1,000$ bp) (4) in DNA extracted from homothallic isolates 95023 and 96012 , but the same band was not amplified from $P$. palmivora or any other tested Phytophthora species (Fig. 3). In addition, the homothallic isolates from loquat were not like the typical homothallic species, which were able to produce a large number of oospores singly. The so-called homothallic isolates (95023, 95034, and 96012) in this study only produced a few oospores (ca. hundreds per $\mathrm{cm}^{2}$ ), and most of these oospores were aborted; whereas the same isolate formed more than 6,000 normal-appearing oospores per $\mathrm{cm}^{2}$ when paired across a polycarbonate membrane with A1 tester (P991) of $P$. parasitica (Table 2). Therefore, we consider their mating type as $\mathrm{H} \rightarrow \mathrm{A} 2$ instead of $\mathrm{H}$ (homothallic).

Based on the results of pathogenicity tests (P. J. Ann, unpublished data), all the tested typical isolates of $P$. parasitica were

Table 4. Pathogenicity of loquat isolates of Phytophthora parasitica to other plants

\begin{tabular}{lcccccc}
\hline & \multicolumn{5}{c}{ Disease incidence $^{\mathrm{a}}$} \\
\cline { 2 - 7 } Isolate no. & Tomato & $\begin{array}{c}\text { Sweet } \\
\text { pepper }\end{array}$ & Cucumber & Tobacco & $\begin{array}{c}\text { Sweet } \\
\text { orange }\end{array}$ & Egg plants \\
\hline $\begin{array}{l}\text { Typical P. parasitica } \\
96085\end{array}$ & $5 / 5$ & $0 / 6$ & $0 / 10$ & $0 / 4$ & $10 / 10$ & $8 / 8+++$ \\
96091 & $4 / 5$ & $0 / 6$ & $0 / 10$ & $0 / 4$ & $10 / 10$ & $8 / 8+++$ \\
Atypical P. parasitica & & & & & & \\
95023 & $0 / 5$ & $0 / 6$ & $0 / 10$ & $0 / 4$ & $5 / 10$ & $8 / 8++$ \\
95034 & $0 / 5$ & $0 / 6$ & $0 / 10$ & $0 / 4$ & $2 / 10$ & $8 / 8++$ \\
96120 & $0 / 5$ & $0 / 6$ & $0 / 10$ & $0 / 4$ & $7 / 10$ & $8 / 8++$ \\
P. palmivora & & & & & & \\
ATCC6144 & $0 / 5$ & $0 / 6$ & $0 / 10$ & $0 / 4$ & $0 / 10$ & $5 / 8+$ \\
\hline
\end{tabular}

${ }^{a}$ No. of plants (fruits) infected per no. of plants (fruits) inoculated. $+++=$ highly virulent, $++=$ moderately virulent, $+=$ weakly virulent. Data were taken 2 weeks after inoculation of 1 -month-old seedlings of tomato, sweet pepper, cucumber, tobacco, and sweet orange, and 1 week after inoculation of eggplant fruits.

Table 5. Difference in characteristics between homothallic and heterothallic isolates of Phytophthora parasitica from loquat

\begin{tabular}{lll}
\hline Characteristics & Homothallic isolates & Heterothallic isolates \\
\hline Colony appearance & Smooth, radiate & Mosaic \\
Caducous sporangia & + & - \\
Oospore sizes & $>30 \mu \mathrm{m}$ & $<30 \mu \mathrm{m}($ except isolate 96120$)$ \\
Growth at $35^{\circ} \mathrm{C}$ or above & - & $+($ except isolate 96120) \\
Pathogenicity to loquat & Strong & None or weak \\
Pathogenicity to tomato & - & $+($ except isolate 96120$)$ \\
Soluble protein patterns & Not identical to $P$. parasitica & $\begin{array}{c}\text { Identical to } P \text {. parasitica } \\
\text { (except isolate 96120) }\end{array}$ \\
\hline
\end{tabular}

pathogenic to their own host plants and to some other plants, such as fruits of eggplant and seedlings of tomato and sweet orange, but not to sweet pepper and tobacco. In the current study, the two homothallic isolates, 95023 and 95034, and isolate 96120 (A2) were very virulent to loquat seedlings (Table 3) but not pathogenic to tomato seedlings (Table 4). On the other hand, isolates 96085 and 96091 of $P$. parasitica from loquat were not very virulent to loquat seedlings (based on results of stem inoculation) and were pathogenic to tomato seedlings. In addition to this, the three isolates highly virulent to loquat were less virulent to fruits of eggplant and citrus seedlings (Table 4), compared with isolates 96085 and 96091 . These data indicate that the three isolates were not completely similar to the typical $P$. parasitica in virulence reactions to the tested host.

According to the results of this research, the homothallic loquat isolates were considered to be atypical strains of $P$. parasitica. They were different, as summarized in Table 5, from the typical $P$. parasitica in: (i) radiate colony appearance without mosaic patterns, (ii) partially caducous character of sporangia, (iii) larger size of oospores, (iv) no growth at 36 to $37^{\circ} \mathrm{C}$, (v) mycelial protein pattern similar but not completely identical, and (vi) pathogenicity, such as being nonpathogenic to tomato seedlings. Isolate 96120 (A2) is more like typical $P$. parasitica than the homothallic isolates, except that growth does not occur at $36^{\circ} \mathrm{C}$, larger oospores (average $>30 \mu \mathrm{m}$ diameter) are produced, and this isolate is not pathogenic to tomato seedlings. These two atypical strains of $P$. parasitica were highly pathogenic to loquat in inoculation tests and were considered to be the cause of the decline and death of loquat trees in Taiwan. Other typical isolates of $P$. parasitica, represented by 96085 (A2) and 96091 (A1) and the $P$. palmivora isolate ATCC6144 (A1) from loquat in Taiwan, only caused fibrous root rot of inoculated loquat seedlings. They might play a role in the disease complex but do not have the ability to cause severe problems alone.

\section{LITERATURE CITED}

1. Ann, P. J., and Ko, W. H. 1996. Survey of enzyme activity on solid media in Phytophthora. Can. J. Bot. 68:139-143.

2. Bielenin, A., Jeffers, S. N., Wilcox, W. F., and Jones, A. L. 1988. Separation by protein electrophoresis of six species of Phytophthora associated with deciduous fruit crops. Phytopathology 78:1402-1408.

3. Chang, T. T., Yang, W. W., and Wang, W. Y. 1996. Use of random amplified polymorphic DNA markers for the detection of genetic variation in Phytophthora cinnamomi in Taiwan. Bot. Bull. Acad. Sin. 37:165-171.

4. Ersek, T., Schoelz, J. E., and English, J. T. 1994. PCR amplification of species-specific DNA sequence can distinguish among Phytophthora species. Appl. Environ. Microbiol. 60(7):2616-2621.

5. Ho, H. H., Ann, P. J., and Chang, H. S. 1995. The genus Phytophthora in Taiwan. Monogr. 
Ser. no. 15. Institute of Botany, Academia Sinica.

6. Hwang, S. C., and Ko, W. H. 1975. A simplified method for sporangial production by Phytophthora cinnamomi. Mycologia 67:1233-1234

7. Ko, W. H. 1978. Heterothallic Phytophthora: Evidence for hormonal regulation of sexual reproduction. J. Gen. Microbiol. 107:15-18.

8. Ko, W. H., Chang, H. S., and Su, H. J. 1978. Isolates of Phytophthora cinnamomi from
Taiwan as evidence for an Asian origin of the species. Trans. Br. Mycol. Soc. 71:496-499.

9. Ko, W. H., Chase, L., and Kunimoto, R. 1973 A microsyringe method for determining concentration of fungal propagules. Phytopathology 63:1206-1207.

10. Laemmli, U. K. 1970. Cleavage of structural proteins during the assembly of the head of bacteriophage T4. Nature 227:680-685.

11. Lin, J. H., Chang, L. J., and Liu, T. T. 1995. Loquat. Taiwan Agricultural Encyclopedia
(Crop-Edition 2). Coun. Agric. ed.

12. Tucker, C. M. 1931. Taxonomy of the genus Phytophthora de Bary. Mo. Agric. Exp. Stn Res. Bull. 153.

13. Waterhouse, G. M. 1963. Key to the species of Phytophthora de Bary. Commonw. Mycol. Inst./Assoc. Appl. Biol., Kew, Surrey, England.

14. Weltzien, H. C., and Schwinn, F. J. 1966 Phytophthora trunk rot on loquat trees, Riobotrya japonica, in Lebanon. Phytopathol. Z. 56:331-339. 